IPTEKS PENGENDALIAN INTERN TERHADAP LELANG BARANG GADAI PADA PT. PEGADAIAN (PERSERO) CABANG KAROMBASAN

\author{
Muh. Rivaldi Dg Lompang ${ }^{1}$, Meily Y.B. Kalalo \\ ${ }^{1,2}$ Jurusan Akuntansi, Fakultas Ekonomi dan Bisnis, Universitas Sam Ratulangi, Jl. Kampus Bahu, Kota \\ Manado, 95115, Indonesia \\ E-mail : rivaldilompang@gmail.com
}

\begin{abstract}
Pegadaian is one of the financial institutions owned by BUMN, where the main business is about credit something with the guarantee that the pawned tools move on the basis of financial law. This material can guarantee absolute rights to certain items of interest which are the object of guarantee of a debt and whenever it can be cashed for the payment of items that have been made in the agreement if it cannot complete the deals of payment. Auction is a sale of items for public place where the price are published in writing or directly, which increases or decreases in order to reach the highest price. The Auction is done if the customer is unable to fulfill his obligation to return or extend the mortgage item, and the Auction will be done in public place. PT. Pegadaian (Persero) has the right to sell the guarantee items belongs customers in an Auction. but before the Auction PT. Pegadaian (Persero) Karombasan Branch will confirm or remind the customer that the items in the pawn have out of date or have passed the payment limit. So the misunderstanding will not happen between the company and the customer.
\end{abstract}

Keywords : procedure for auctioning goods pawned

\title{
1. PENDAHULUAN
}

Organisasi menggantungkan diri pada suatu sistem informasi yang dapat berdaya saing. Produktivitas yang di hasilkan dapat mempengaruhi faktor terpenting pada perusahaan sehingga daya jual lebih baik. Perusahaan harus menggunakan sistem informasi yang lebih hebat. Dengan adanya sistem informasi akuntansi yang jelas maka manajemen dalam organisasi yang terdapat pada perusahaan dapat berjalan dengan lancar sehingga perusahaan dapat berjalan dengan efektif dan efisien. Sistem informasi akuntansi (SIA) ini juga dipakai sebagai panduan dalam penempatan dan otoritas bagi sumber daya manusia (SDM) yang berkarya dalam suatu organisasi atau perusahaan tersebut, sehingga dapat dijalankan sesuai dengan prosedur. Agar dapat berjalan secara efektif dan efisien dalam pelelangan gadai PT. Pegadaian (Persero) Cabang Karombasan maka sistem informasi akuntansinya harus dapat diandalkan. Berdasarkan uraian diatas penulis tertarik untuk mengetahui bagaimana praktek dan penerapan pengendalian internal lelang barang gadai pada PT. Pegadaian Cabang Karombasan.

\section{TINJAUAN PUSTAKA}

Gadai. Gadai merupakan seseorang yang menerima pinjaman uang atau benda yang bisa bergerak, degan syarat adanya barang/benda yang bisa dijadikan jaminan atas nama peminjam yang bersangkutan. Kemudian peminjam yang bersangkutan memiliki kewajiban melunasi sejumlah pinjaman yang ia pinjam kepada pihak yang bersangkutan, dan apabila pinjaman tersebut tidak dilunasi, maka pihak yang memberikan pijaman memiliki hak untuk melelang barang/benda tersebut sesuai dengan kessepakatan yang telah dibuat sebelumnya, sebelum seseorang tersebut menerima sejumlah dana pinjaman. 
Pengertian Lelang. Lelang menurut Kamus Besar Bahasa Indonesia (KBBI) ialah ketua/pejabat lelang yang memimpin diadakannya penjualan di depan orang-orang (dengan permintaan paling tinggi). Sementara melelangkan/memperlelangkan mempunyai arti:

- Melakukan lelang degan cara penjualan

- Penjualan yang dilakukan dalam lelang dengan jalan pelelangan.

- Mengumpulkan sekaligus proyek

Dari penjelasan diatas bisa disimpulkan jika dalam penjualan lelangterdapat juga kumpulan sejumlah proyek, yang dimana bukan cuma dalam batasan penjualan barang saja. Sementara lelang menurut dictionary of law yang di translate ke dalam english language, lellang merupakan aksi, yakni "Public sale at white goods are sold to the person making the highest bids or offers", sementara jikadalam Indonesia language ialah penawar tertinggi yang bisa mendapatkan barang yang dijual di depan banyak orang atau di khyalak umum. Penjualan yang dilakukan dihadapan umum degan megumpulkan mereka yang memiliki keinginan dalam lelang merupakan keuntugan yang paling besar yang bisa didapatkan oleh penjual, yang dimana bisa menjadi sarana dalam mendapatkan persetujuan dan perjanjian.

Sistem Pengendalian Intern. Tolak ukur dalam aktivitas operasi kerja menjadi pedoman pada segala mode oprasional dalam satuan kerja pegadaiaan yang dimana sudah merekat system pengendaliian internal yang sudah sesuai. Efektivitas internal control dalam satuan kerja yang dibahas kembali secra periodic pada kantor pusat dan kntor oleh intern supervisor. Peningkatan kuwalitas dan pengoprasian system internal control merupakan tanggungjawab dan tugas penting dari semua karyawan/pegawai serta manajemen. Pegadaian saat ini sudah mempunyai kebijakan dalam internal control system yang melingkupi beberapa faktor yakni:

- Dikembangkannya adat paham resiko dan pengamatan dari manajemen.

- Pengenalan dan penaksiran risiko.

- Aktivitas the risk control dan pembagian tugas.

- Accounting system, Information and communication.

- Aktivitas pengamatan dan kegiatan perbaikan penyelewengan.

\section{METODE DAN TEKNIK PENERAPAN IPTEKS}

\subsection{Metode Penerapan Ipteks}

Metode penerapan ipteks dalam pengendalian intern terhadap lelang barang gadai pada PT. Pegadaian (Persero) Cabang Karombasan.

\subsection{Teknik Penerapan Ipteks}

Teknik ipteks yang diterapkan adalah teknik analisis yang mendeskripsikan atau menggambarkan penerapan pengendalian intern menurut COSO pada kegiatan lelang barang gadai PT. Pegadaiian (Persero) Cabang Karombasan.

\section{PEMBAHASAN}

\subsection{Gambaran Objek Penerapan Ipteks}

Tuntutan pada zaman saat ini adalah perkembangan teknologi di era global yang menuntut semua transaksi serba cepat, termasuk pelayanan pembiayaan keuangan. Agar supaya transaksi dapat dilakukan lebih cepat tanpa harus menunggu lama.Dengan adanya terobosan baru pada PT. Pegadaian (Persero) mulai melakukan transformasi perusahaan dalam upaya menjadi financial company melalui strategi G5 Star Generation di usianya ke117 tahun ini. Langkah perubahan ini dapat ditandai dengan adanya peluncuran Pegadaian Digital Service (PDS) untuk mendekatkan produk Pegadaian ke generasi milenial.

\subsection{Pembahasan}

Untuk mengetahui pengawalan Internal pada lelang gadai yang diterapkan oleh PT. Pegadaian (Persero) Cabang Karombasan telah memadai yang berjalan sesuai dengan 
fungsinya, kemudian penulis mencoba menganalisa sesuai pertimbangan COSO (Committee of Sponsoring Organizations of Treadway). Proses Pengendalian Internal ini kemudian dibagi menjadi lima elemen yang sesuai $C O S O$ yaitu:

a. Lingkungan Pengendalian. Lingkungan Pengendalian yang terdapat pada Organisasi adalah faktor pertama dari lima komponen pengendalian internal, yang membentuk dari beberapa facktor-faktor pengendalian sistem yang ada. Lingkungan pengendalian merupakan efek kumulatif atas aspek-aspek untuk membangun, membawa dan meninggikan kearifan dan prosedur tertentu. Kegiatan lelang barang gadai faktor-faktor pengendalian lingkungan terlihat pada:

- Struktur organisasi yang telah disusun. Struktur Organisasi PT. Pegadaian (Persero) Cabang Karombasan dapat dideskripsikan sebagai kekuasaan dan tanggung jawab pada organisasi, struktur organisasi resmi seringkali digambarkan dalam sketsa organisasi.

- Cara memberikan wewenang dan tanggung jawab. Metode pembagian wewenang dan tanggung jawab pada PT. Pegadaian (Persero) Cabang karombasan memiliki dua metode yaitu informal dan formal dengan menggunakan dokumen tercantum.

- Pemisahan fungsi, penulisan yang berdasarkan komponen-komponen pada PT. Pegadaian (Persero) Cabang Karombasan, tugas kas dipegang oleh dua unit organisasi yaitu bidang lelang dan bidang kasir, kemudian pelaksanaan kegiatan berjalannya lelang juga menangani penerimaan kas. Dalam serah terima pendapatan lelang yang dilakukan bagian lelang ke bagian kasir belum ada pencatatan khusus atau dokumen tertentu sebagai tanda bukti.

- Etika budaya kerja. PT. Pegadaian Cabang Salemba mempunyai adab yang terkait etika dan budaya kerja. Etika budaya PT Pegadaian (Persero) dapat diaktualisasikan pada beberapa format lambang/maskot dan slogan si "INTAN" yang bermakna: Kreatif, Nilai Moral Tinggi, Kompoten, Layanan, dan Citra. Pandangan dari budaya kerja tersebut terdapat dalam website Pegadaian, sebagai contoh jika terjadi penyimpangan, maka akan mendapat sanksi sesuai dengan kesalahannya.

b. Penaksiran Resiko. Penaksiran Resiko adalah proses identifikasi, menguraikan, dan mengendalikan risiko sehingga mempengaruhi tujuan dari perusahaan. Tingkatan paling kritis dalam memperkirakan risiko adalah mengenali aktivitas yang diperlukan. Prosedur lelang barang gadai PT. Pegadaian Cabang Karombasan, analisa taksiran ini merupakan landasan paling utama pada kegiatan lelang barang gadai, sangat berguna ketika untuk menilai suatu barang yang akan dilelang, mengukur keadaan barang, golongan dan jenis barang serta menaksir harga apakah barang tersebut dapat menutupi pengembalian uang pinjaman dan sewa modalnya. Oleh karena itu dalam kegiatan lelang barang yang digadai di PT. Pegadaian (Persero) Cabang Karombasan ada 4 komponen prosedur lelang yaitu:

- Bagian gudang, adalah pemegang yang mengadakan barang yang dilelang

- Bagian lelang, adalah bagian yang memastikan harga estimasi lelang

- Bagian kasir, adalah bagian yang mengumpulkan hasil produk lelang

- Bagian administrasi, adalah bagian yang mebereskan hasil para pemenang lelang

c. Aktivitas Pengendalian. Aktivitas pengendalian merupakan salah satu kearifan dan kebijakan dibuat untuk dapat menegaskan bahwa administrasi yang dilaksanakan bias berjalan dengan baik. Pada aktivitas pengendalian kegiatan lelang barang yang ada di PT. Pegadaian (Persero) Cabang Karombasan dapat dilihat :

- Dokumen dan catatan pada PT. Pegadaian (Persero) Cabang Karombasan yang digunakan sebagai bentuk fisik dari transaksi yang berkaitan atas kegiatan lelang, kemudian menjadi pegangan perusahaan yang mengejawantahkan informasi berbentuk Laporan Keuangan ataupun laporan pada umumnya dan pertimbangan. 
- Pengecekan akuntabilitas dan apresiasi penampilan oleh pihak Independen. Contoh pemeriksaan independen yang dilakukan oleh pihak Satuan Pengawas Intern.

- Penetapan harga minimal lelang barang gadai, merupakan pedoman dalam menetapkan harga suatu barang yang akan dilelang menurut taksiran yang ada.

d. Informasi dan Komunikasi. Informasi pada sistem akuntansi organisasi, terdapat beberapa formula dan tulisan yang dibuat untuk mengenali, mencocokan, mencatat, menjabarkan, menghimpun, dan memberitakan negosiasi organisasi untuk menjaga akuntabilitasnya. Transaksi akuntansi pada PT. Pegadaian (Persero) Cabang Karombasan dilakukan menggunakan teknologi komputerisasi agar proses pengolahan datanya cepat dan teratur. Dalam pemberitahuan pengumuman pelaksanaan lelang barang yang di gadai dapat dilihat melalui situs website www.pegadaian.co.id.

e. Pengawasan. Pengawasan atau monitoring, adalah salah satu dari lima faktor pengendalian internal, proses ini berkelanjutan agar dapat memperkirakan kapasitas pengendalian internal dari waktu ke waktu untuk mengambil suatu tindakan agar dapat mengoreksi yang diperlukan. Pengawasan yang dilakukan pada perusahaan Pegadaian dilakukan oleh OJK. Bentuk pengawasan yang dimaksud oleh pasal 41 tersebut, OJK dapat melakukan pemeriksaan terhadap perusahaan pegadaian dengan cara menugaskan pegawai OJK atau pihak lain, atau gabungan antara pegawai OJK dan pihak lain yang telah ditunjuk oleh OJK untuk melakukan eksplorasi.

\section{KESIMPULAN DAN SARAN}

\subsection{Kesimpulan}

Berdasarkan analisis yang dilakukan penulis, maka dapat disimpulkan pada pelaksanaan sistem informasi akuntansi (SIA) yang telah diimplementasikan PT. Pegadaian (Persero) Cabang Karombasan yang mempunyai praktek dari beberapa faktor guna membawa sistem informasinya yaitu; factor yang mempengaruhi (SDM), fail yang digunakan adalah penulisan akuntansi, prosedur lelang, laporan yang dihasilkan dan pengawasan internal yang cukup memadai dan berjalan sesuai tugas pokok dan fungsi. Sedangkan dari hasil analisa dengan menggunakan rekomendasi COSO(Committee of Sponsoring Organizations of Treadway Commission) yang terdiri dari lima faktor dapat diketahui bahwa sistem Pengendalian Internal yang diterapkan PT. Pegadaian (Persero) Cabang Karombasan terhadap lelang barang yang digadai sudah cukup memadai.

\subsection{Saran}

Berdasarkan penerapan ipteks maka dapat disarankan kepada PT. Pegadaian (Persero) agar dapat mengevaluasi kembali terhadap sewa modal yang ditawarkan PT. Pegadaian (Persero) relatif lebih tinggi tingkat bunganya dan harus ada jaminan barang yang mempunyai nilai jual. Mungkin itu adalah salah satu dari beberapa kekurangan yang sangat memberatkan nasabah untuk melakukan transaksi, semoga dengan adanya beberapa masukan dapat membuat PT. Pegadaian (Persero) menjadi salah satu perusahaan yang terdepan di Indonesia.

\section{DAFTAR PUSTAKA}

Aziz, dan Mukhlis, A., (2013). Analisis Pengaruh Tingkat Sewa Modal. Jumlah Nasabah, Harga Emas, dan Tingkat Inflasi Terhadap Penyaluran Kredit Gadai Golongan C (Studi Kasus pada PT. Pegadaian Cabang Purbolinggo). Jurnal Akuntansi (hlm, 4-5).

Bodnar, G.H. dan William S.H.,(2000). Accounting Information System. Edisi-6. Jakarta: Salempa Empat. 
Dedy. P., (2016). Analisis System Pengendaliian Intern pada Lelang Barang Gadai Pada PT. Pegadaian (Persero) Cabang Jember. Skripsi Universitas of Muhamadiyah Malang

Hanin, W. D., dan Siryadi. (2016).Pengaruh Kuwalitas Pelayanaan pada Kepuasan Nasaba Pada PT. Pegadaian (Persero) Cabang Kendal.

Hidayat, Windiyani. 2010. Analisis Penerapan Information System Akuntansi dan internal control Pembiayaan murabahah Bank DKI Unit Usaha Syariah. Skripsi. Jakarta:Universitas Gunadrama.

https://www.pegadaian.co.id

https://www.ojk.go.id

Pontoh, W., dan Makaluas, J. L., (2018). Pengendalian Intern Aset Tetap Pada PT. Lumbun Berkat Indonesia. Pedoman Kantor Cabang, Pedoman Operasional Kantor Cabang (POCK), Penerbit Kantor Pusat PT. Pegadaian. Salemba Empat,: Jakarta.

Qomariyah, dan Siti Nurul. (2011) Analisis dan Perancangan Sistem Informasi Akuntasi Penjualan Tunai (Studi Kasus Pada Toko Central Tas). Skripsi. Jakarta: Universitas Gunadarma.

Romney dan Steinbarth. (2006).Accounting InformationSystem. Buku-1 ,Edisi-9. Salemba Empat,:Jakarta.

Rahmayanti, dan Dwi., (2012). Analisis Sistem Informasi Akuntasi dan Pengandalian Internal Terhadap Lelang Barang Gadai di Perum Cabang Salemba. Skripsi Fakultas Ekonom. Universitas Gunadarma.

Sajady, H. and M. Dastgir., "Evaluation of the Effectiveness of Accounting Information Systems.” International Journal of Science \& Technology, Vol .6, 2008.

Wilkinson, J.W, dan Cerullo. 2000. Accounting Information Systems (Sistem Informasi Akuntansi). Edisi Keempat. Jakarta. 